\title{
Evaluation of the Lingual Canals of Mandible in Cone Beam Computed Tomography
}

\author{
ANDREI LEONID CHIRITA', MUGUREL CONSTANTIN RUSU1', RUXANDRA STANESCU², GABRIELA TANASE2, MIHAI BUTUCESCU²*, \\ MIHAI PREDOIU ${ }^{1}$ \\ ${ }^{1}$ Carol Davila University of Medicine and Pharmacy, Faculty of Dental Medicine, Division of Anatomy, 8 Eroii Sanitari Str., 050474, \\ Bucharest, Romania \\ ${ }^{2}$ Carol Davila University of Medicine and Pharmacy, Faculty of Dental Medicine, Division of Implantology, 8 Eroii Sanitari Str., \\ 050474, Bucharest, Romania
}

\begin{abstract}
This study aims to assess the frequency of the lingual foramina and canals relative to their location on the mandibular cortical plate and also to closely inspect the course of the lingual canals inside the mandibular body using 3D reconstruction of the evaluated area. A retrospective study was conducted with 55 cone bean computed tomography (CBCT) scans in order to analyze the location, number, course and anastomosing pattern of the lingual canals. A total number of 165 lingual canals (LCS) were recorded from 55 patients, as follows: 94 median (MLC), 16 paramedian (PLC) and 55 lateral lingual canals (LLC). MLCs were a constant finding in all 55 patients (100\% of the cases), PLCs were present in 15 patients (27.3\% of the cases), and LLCs were identified in 35 patients (63.3\% of the cases). The anastomosing pattern of the MLC, in which a supraspinous canal anastomosed with an infraspinous canal, was found in 10.9\% of the cases (6 of 55 patients),. The LLCs were anastomosed with the mandibular incisive canal (MIC) in 56.3\% of the cases (31 of 55 LLCS) and with the mandibular canal (MC) in $3.6 \%$ of the cases (2 of 55 LLCS). CBCT revealed itself to be a reliable tool for evaluating the intramandibular topography of the $L C S$. The anastomosing pattern of the lingual canals might raise the question whether the LCs could be responsible for incomplete anesthesia after conventional mandibularblock by carrying sensoryinnervation from the mylohyoid nerve to the inferior alveolar nerve.
\end{abstract}

Keywords mandible, lingual canal, intramandibular anastomosis, CBCT

Lingual canals (LCS) were first documented by Hirschfeld et al. [1], who described them as interdental canals with vascular content that descended from the lingual cortical plate in the mandibular body, between the central and the lateral incisor. The foramen located in the genial tubercles region was described by Ennis et al. [2], from 1937, as a nutrient foramen. Some classifications of LCs were made based on their foramina localization on the mandibular body internal surface. Those in the midline were termed median lingual canals (MLCs), paramedian lingual canals (PLCs) were situated between the midline and canine's distal surface, and lateral lingual canals (LLCs) were placed distally to the canine. MLCs can be located either above, betw een or below the mental spines [3].

MLCs were a constant finding in all studies, being found in $100 \%$ of the cases [4-7]. The number of LCs situated on the midline varied from 1 to $4[8,9]$, but most frequently one $[5,10]$ or two $[6,11]$ canals were identified. A recent study designed to report on lingual foramina and canals evaluated exclusively those in the anterior mandible [12], butseemingly the LCs were overlooked. This could explain why in 6/90 mandibles the LCs and foramina could not be located [12]. Therefore, when identifying LCs and foramina, the interforaminal mandibular region should be investigated, rather than just the anterior mandible. When only one MLC was seen, it was usually situated above the genial tubercles, and when two MLC were noticed, one was situated above and the other below the mental spine $[4,8,9]$.
PLC and LLCs seem less frequent than MLCs, with a prevalence ranging between 6 and $80 \%$ [3]. The LLCs were often situated in the premolar area. In $50 \%$ of the cases [6, 9], studies found LLCs located above the premolars, and in $70 \%$ of the cases the LLCs [13] were placed in the mental foramen area. The paramedian localization of the LC was observed by von Arx etal. [11], who found PLCs in $9.7 \%$ of cases.

The content of MLCs was studied by McDonnell et al. [14], who found an arterial anastomosis, resulting from the sublingual artery and its contralateral branch, entering the supraspinous foramen. Different studies found neurovascular content in MLCs [15], with the mylohyoid nerve entering the infraspinous median lingual foramen (16), while the supraspinous foramen was speculated from histology slides to contain branches of the lingual nerve and artery [17].

We hypothesized that the anatomy of LCs is consistently documented and should not differ significantly between ethnic groups. We therefore aimed to study the prevalence of different patterns of LCs in a Romanian sample and to compare the results with those resulted from previous studies.

\section{Experimental part \\ Material and ethod}

A retrospective study was conducted on 55 archived files of Romanian patients who had undergone dental CBCT scans. The patients were between 27 and 70 years old, with a group average of 42 years. The archived files

* email: mihai.butucescu09@gmail.com 
belonged to 29 females and 26 males, who were analyzed in the study. The scans were made, as in previous studies [18-21], with an iCat CBCT machine (Imaging Sciences International) using the following settings: resolution 0.250 , field of view 130, image matrix size $640 \times 640$, sensor dimensions $20 \times 25 \mathrm{~cm}$, and grayscale resolution 14 bits. The voxel dimension was set on $0.250 \mathrm{~mm}$ and the acquisition time on 13.9 seconds. The files collected were converted in a DICOM format, as in other previous studies [22-27], and were further evaluated using the Planmeca Romexis Viewer 3.5.0.R software. The patients' mandibles were investigated in bidimensional multiplanar reconstructions (MPRs): axial, coronal and sagittal. Threedimensional volume renderizations were also used to evaluate the morphology of the intramandibular canals.

The results for all 55 patients were included in a table containing the following information for each patient: the number of MLCs and their position relative to the mental spine (supraspinous, interspinous or infraspinous). The direction in the vertical plane (ascending, horizontal or descending) and in the horizontal plane (anterior or lateral) were also included in the table. The LLCs' number and position relative to the teeth and the direction in the vertical and horizontal planes (as for the MLCs) were additional parameters taken into consideration for the table. The anastomosing pattern of the lingual canals was also observed, and each anastomosis between a lingual canal and another intramandibular canal was registered in the same table.

All of the examined patients gave their informal consent, according to which their medical data could be used for research and for teaching purposes, as long as the patients' identities were protected.

\section{Results and discussions}

A total of $165 \mathrm{LCs}$ were identified in 55 patients. One LC was found in $14 \%$ of the patients $(n=8)$, two in $24 \%$ of the patients $(n=13)$, three in another $24 \%$ of the cases $(n=13)$, four LCs occurred the most often, in $27 \%$ of the patients $(n=15)$, five were identified in $9 \%$ of the cases $(n=5)$, and one patient ( $2 \%$ of the cases) had seven LCs (fig. 1).

MLCs were a constant finding, every patient having at least one MLC. There were 94 MLCs: 54 supraspinous, 10 interspinous and 30 infraspinous (fig. 2). All of the MLCs had an anterior direction in the horizontal plane. In the vertical plane, the supraspinous canals were descending in $100 \%$ of the cases $(n=54)$, the interspinous canals had a horizontal course in $50 \%(n=5)$ and a descending course in the other $50 \%$ of the cases $(n=5)$, and the infraspinous canals had an ascending course in 93\% $(n=28)$ and a horizontal course in $7 \%$ of the cases $(n=2)$.

PLCs were observed in $27.3 \%(n=15)$ of the cases; they were always single and unilateral, excepting one case when a patient had 2 PLCs that were found on the same side (in the canine area), making 16 PLCs in total. On the right side, they were seen in 6 patients, all of them being positioned in the canine area. On the left side, PLCs were observed in 9 patients, 7 of them presenting a PLC in the canine area and 2 patients having a PLC in the lateral incisor area. The direction of the PLCs in the horizontal plane was anterior in $94 \%$ of the cases $(n=15)$ and lateral, perpendicular to the lingual cortical plate, in $6 \%$ of the cases

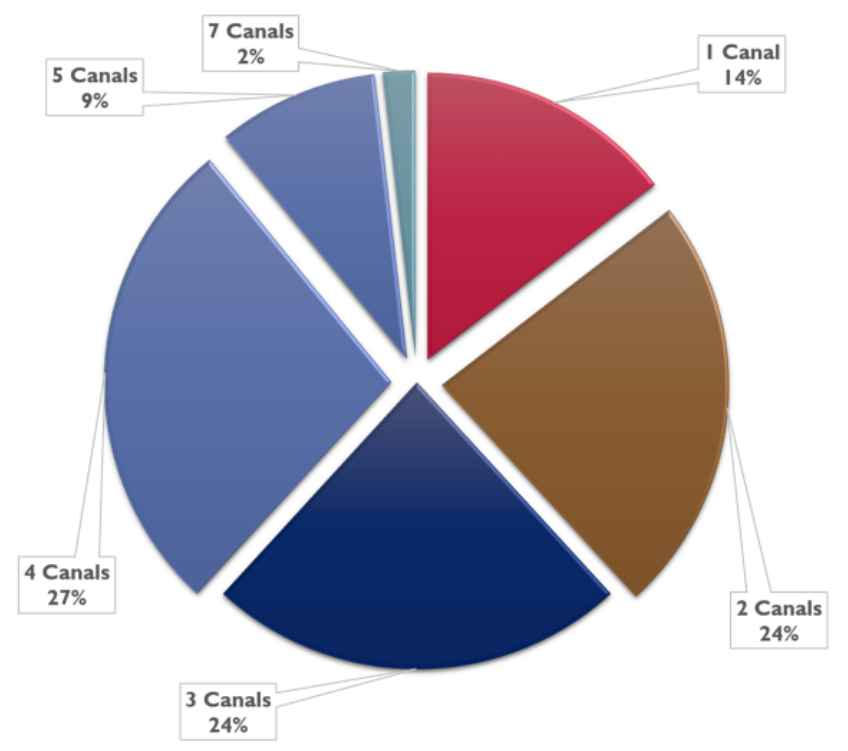

Fig. 1 The graphic representation of the total number of the patients divided in 6 groups, depending on the number of the lingual canals

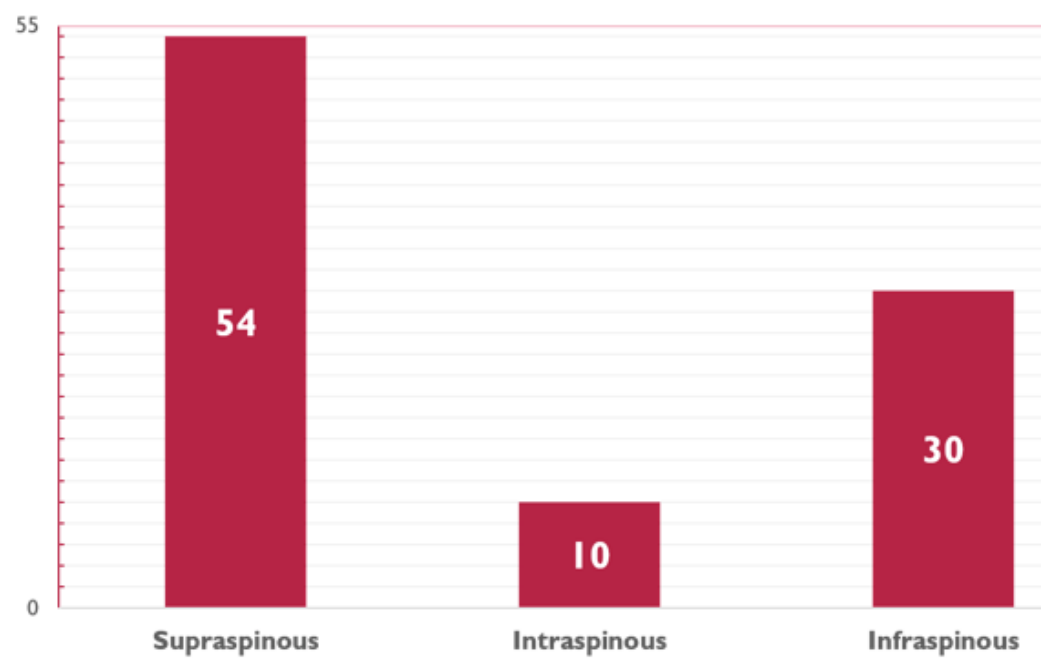

Fig. 2 The graphic representation of the total number of the median lingual canals $(N=94)$, depending on their position relative to the mental spine. 
$(n=1)$. In the vertical plane, $69 \%(n=11)$ had a descending course from the paramedian foramina, and $31 \%(n=5)$ had a horizontal course.

LLCs were found in 35 patients ( $63.6 \%$ of the patients), 27 on the right side $(50 \%)$ and 25 on the left side (45.5\%). A total of 55 LLCs were identified, ranging between 1 and 3 per patient and 1 and 2 per side. In $51 \%$ of the cases $(n=18)$, only one LLC was seen per patient, 2 LLCs were identified in one patient in $40 \%$ of the cases $(n=14)$, and in $9 \%$ of the cases $(n=3), 3$ LLCs were present in the same patient. On the rightside, $28 \mathrm{LLCs}$ were seen in 27 patients, the most common localization being the premolar area. The LLCs' frequency on the right side was $7.3 \%$ in the first premolar area ( $n=4$ canals), $29 \%$ in the second premolar area ( $n=16$ canals), and $14.5 \%$ in the first molar area $(n=8$ canals) (fig. 3). On the left side, 27 canals were identified in 25 patients with a frequency of $9 \%$ in the first premolar area ( $n=5$ canals), $32.7 \%$ in the second premolar area $(n=18$ canals), and $7.3 \%$ in the first molar area $(n=4$ canals) (fig. 3).

The LLCS were unilateral in $51 \%$ of the cases ( 18 patients) and bilateral in $49 \%$ of the cases (17 patients). Symmetrical bilaterally LLCs were found in $20 \%$ of the cases ( $n=7$ patients). The symmetrical bilaterally LLCS were most often seen situated in the PM2 area ( 5 patients)

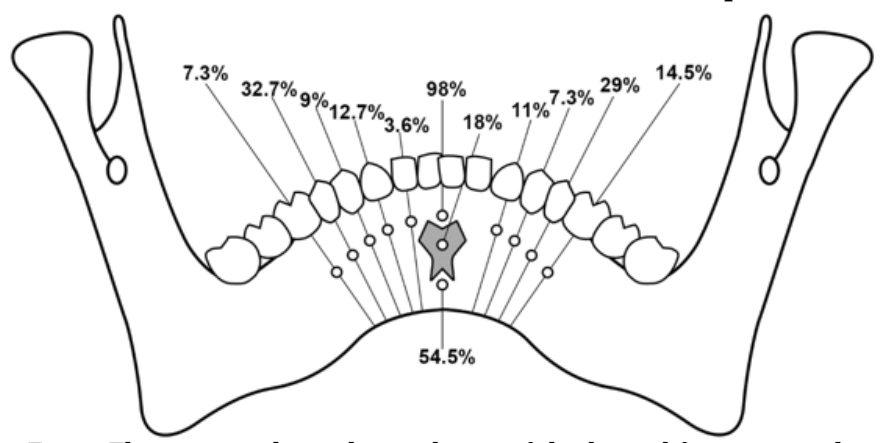

Fig. 3. The topography and prevalence of the lingual foramina and canals, relative to the mandibular tooth.

and less often in the PM1 (1 patient) and M1 (1 patient) areas. The direction in the horizontal plane of the LLCS was anterior in $98 \%$ of the cases $(n=54)$ and lateral in $2 \%$ of the cases $(n=1)$, perpendicular to the lingual cortical plate. In the vertical plane, $67 \%$ of the LLCs had an ascending course $(n=37), 29 \%$ had a horizontal course $(n=16)$, and $3.6 \%(n=2)$ had a descending course in the mandibular body.

Intramandibular anastomosis of the MLCs was reported in 6 patients ( $10.9 \%$ of cases), where a descending supraspinous MLC was observed to be anastomosing with an ascending infraspinous MLC (fig. 4). The PLCs were seen anastomosing with the mandibular incisive canal (MIC) in $25 \%$ of the cases $(n=4)$. The LLCs were communicating with other intramandibular canals in $60 \%$ of the cases ( $n=33)$. In $56.3 \%$ of the cases $(n=31)$, the anastomosis was found between an LLC and the MIC (fig. $5)$, and in $3.6 \%$ of the cases ( $n=2)$, the anastomosis of the LLCs was along the mandibular canal (MC) (fig. 6).

Each of the 55 patients included in this study had at least one LC, and when only one was present, it was an MLC. On the anatomical midline, the highest frequency was found in the supraspinous lingual canal, in $98 \%$ of the patients $(n=54)$. Second, the occurrence of the infraspinous lingual canal was $54.5 \%(n=30)$, and third, the interspinous lingual canal had an incidence of $18 \%$ $(n=10)$. Similarly, Tagaya et al. and Katakami et al. (13, 28) found the supraspinous canal in $95 \%$ of the studied

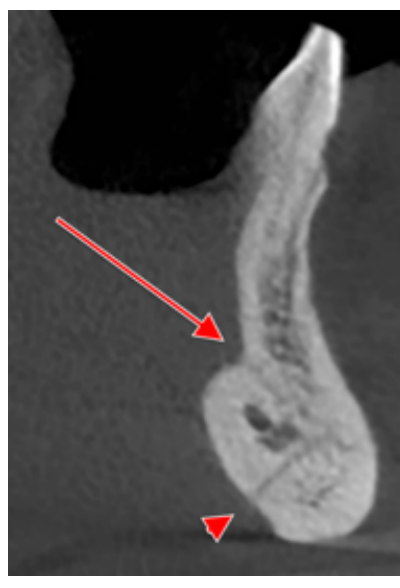

Fig.4. Mediosagittal MPR depicting anastomosed supraspinous (arrow) and infraspinous (arrowhead) canals.

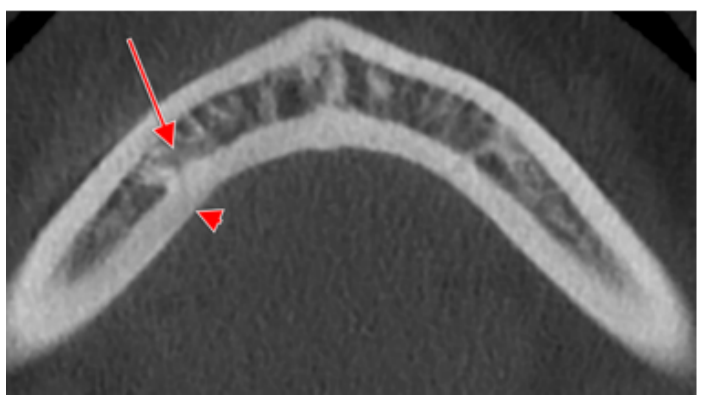

Fig.5. Axial MPR of the mandible depicting a lateral lingual canal (arrowhead) which anastomoses with the incisive mandibular canal (arrow)

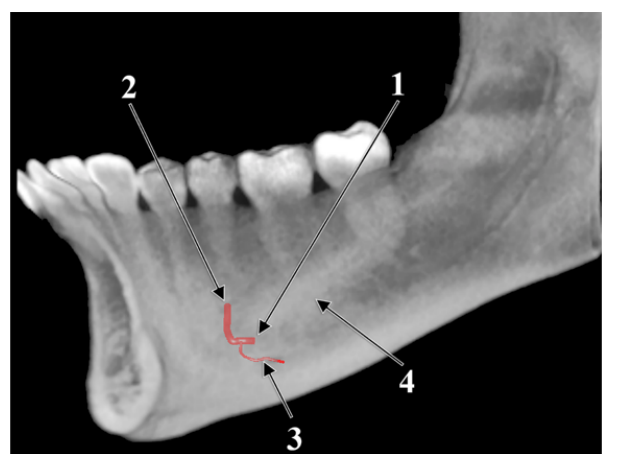

Fig.6. Three-dimensional volume renderization of the right hemimandible, internal view. 1.mandibular canal; 2.mental canal; 3.lateral lingual canal; 4.mylohyoid line.

cases, the infraspinous canal in 57\%, and the interspinous canal in 49.5\%. The number of MLCs range between 1 and 3 in the current study, with the presence of 2 MLCs in $53 \%$ of the patients ( $n=29$ ) and 1 canal in 38\% of the patients $(n=21)$. This finding is in accordance with Naitoh et al.'s (6) study, which also found a range of MLCs from 1 to 3 , with the highest occurrence being 2 MLCs, which were seen in $53.6 \%$ of his cases. Tepper et al. (5) also found MLCs between 1 and 3 MLCs, but in most of the cases, $64.3 \%$, he found $1 \mathrm{LC}$ situated on the anatomical midline. Examining 36 patients using CBCT, Babiuc et al. (7) found from 1 to $4 \mathrm{MLCs}$, with the highest occurrence being 1 MLC, in $71.9 \%$ of the study's cases. The absence of the $\operatorname{MLC}$ was also reported $(10,11,29-31)$, varying between 2 and $9.6 \%$.

For oral implantology, it is very important to know the anatomical configuration and its variation areas and structures of risk to manage the complications that can appear during surgical procedures. These complications include bleeding, infection and neurosensory deficit; it is necessary to evaluate with CBCT the position of the neurovascular canals in order to avoid damaging their content. 
In the vertical plane, the course of the MLCs followed a pattern also found in other studies [7, 10]. Liang et al. [10] shows in his work that supraspinous canals are descending in $77.8 \%$ of the reported cases and that infraspinous canals have an ascending course in $91.9 \%$ of the cases. The current study found $100 \%$ of the supraspinous canals having a descending course, and $91.9 \%$ of the infraspinous canals having an ascending course.

PLCs were present in $27.2 \%$ of the studied cases $(n=15)$. The most common localization was the canine area, being identified with a frequency of $11 \%$ below the right canine and $13.7 \%$ below the left canine. Von Arx et al. [11] calculated a frequency of $7.4 \%$ for PLCs below the right canine and of $14.9 \%$ below the left canine, also finding PLCs with a frequency of $8.2 \%$ and $10 \%$ below the right and left lateral incisors, respectively. In the current study, below the lateral incisor, PLCs were seen only on the left side, with a frequency of $3.6 \%$. Liang etal. [10] found PLCs in $62 \%$ of the reported cases ( $n=31$ jaws), and from those 31 cases, 15 had bilateral PLCs, 8 had PLCs on the right side only, and another 8 had PLCs on the left side only.

The current study found LLCs in $63.6 \%(n=35)$ of the patients and in $47.2 \%(n=52)$ of sides. By examining 28 patients who had undergone the CBCT procedure, Naitoh etal. [6] found LLC in $64.3 \%$ of patients $(n=18)$ and in $50 \%$ of sides $(n=28)$. Tepper et al. [5] used 70 CT scans and identified LLC in $52.9 \%$ of the cases and in $30.7 \%$ of sides. A higher occurrence of the LLCs was discovered by Tagaya et al. [13], who studied 200 patients using CT scans and found LLCs in 160 patients ( $80 \%$ of the cases). The number of LLCS in this study ranges between 0 and 3 per patient and from 0 to 2 per side. Tepper et al. [5] observed 2 LLCs on the same side in $8.6 \%$ of the cases, 1 LLC in $44.3 \%$ of the patients, and no LLC in $47.1 \%$ of the patients. The absence of LLCs in this study was noticed in $36.4 \%$ of the cases. One LC was seen in $32.7 \%$ of the cases $(n=18), 2$ canals in $25.4 \%(n=14)$, and 3 canals were found in $5.4 \%$ of the cases $(n=3)$.

The localization of LLCs was often identified in the premolar area, both in this and in other studies. This study registered the presence of LLCs with a frequency of $36.3 \%$ in the right premolar area and $41.7 \%$ in the left premolar area. Von Arx et al. (11) found LLCs in the premolar area with a frequency of $51.4 \%$ on the right side and $35.3 \%$ on the left side. LLCs were seen with less frequency by Katakami et al. [28]: $27.7 \%$ in the right premolar area and $28.5 \%$ in the left premolar area. Even if some authors [11, 32] found LLCs both in the second and in the third molar areas, the current study shows that LLCs most distal location is the first molar area.

The bilateral aspect of LLCs' has been addressed in other studies [5, 9, 13], but none of the studies discussed bilateral symmetry. Naitoh et al. [ 6 ] found 28 LLCs in 28 sides in the premolar area of 18 patients, $55.5 \%$ of them having bilateral LLCs. This study found bilateral LLCs in $49 \%$ of the cases $(n=17)$ and identified bilateral symmetry in $20 \%$ of them $(n=7)$. Bilateral symmetry was noticed in $14 \%$ of the cases $(n=5)$ in the second premolar area; in $3 \%$ of the cases $(n=1)$, the bilateral symmetry was observed in the first molar and first premolar areas.

The direction of the LLCs in the horizontal plane was registered in the current study as follows: anterior in $98 \%$ of the cases $(n=54)$ and lateral, perpendicular to the lingual cortical bone, in $2 \%$ of the cases. Other reports [11] found a perpendicular orientation to the lingual cortical plane in $22.3 \%$ of the LLCs studied, a posterior orientation in a recurrent manner in $0.8 \%$ of the LLCS, and an anterior orientation in $76.9 \%$ of the LLCs. In the vertical plane, the position according to the anatomical midline may influence the direction of the LCs. It was shown in this study that PLCs which are closer to the midline have a descending course in $69 \%$ of the cases, while in $31 \%$ of the cases they have a horizontal course. LLCs which are further aw ay from the midline have an ascending course in $67 \%$ of the cases, a horizontal course in $29 \%$ of the cases, and a descending course in $3.6 \%$ of the cases. This finding might be explained by PLCs being localized higher than the LLCS, from the lower mandible border on the lingual cortical bone [11].

The anastomosis of LCs with other canals in the mandibular body was discussed by von Arx etal. [11], who found LLCS anastomosing with other canals in $62.8 \%$ of the studied cases. LLCs were seen most frequently, in $64.5 \%$ of the cases, anastomosing with the MIC; in $28.9 \%$ of the cases, LLCs were communicating with the MC; and in $5 \%$ of the cases, LLCs were identified as being linked to a dental apex. This study found $25 \%(n=4)$ of the PLCs and $56.3 \%(n=31)$ of the LLCs studied anastomosing with the MIC. Anastomosis between the LLC and MC was identified in $3.6 \%(n=2)$ of the cases. The anastomosis of LLCs with the MIC was observed by Carter and Keen (1971) [33], who found, below the premolars, a communicating branch of the mylohyoid nerve that traverses the lingual cortical bone through an LC for anastomosing with the incisive branch or plexus of the inferior alveolar nerve. Carter and Keen (33) assumed these canals were used for the anastomosis of the mylohyoid nerve and incisor plexus and compared their findings to those of Shiller and Wiswell (1954) [34] and Shirai (1960) [35].

In the symphyseal area, the supraspinous canal was identified to anastomose with the infraspinous canal in 6 cases. This anastomosing pattern, of a supraspinous canal contacting an infraspinous canal in the mandibular body, could be caused by an arterial arcade from which small arterial branches spread out in order to irrigate the anterior region of the mandibular bone and periosteum [3].

Most lingual, sublingual and submental hemorrhagic incidents are caused by iatrogenic manipulation during different medical procedures, such as implant surgery. A massive hemorrhage in the floor of the mouth caused by damaging these arteries during an implant drilling procedure will cause an elevation of the floor of the mouth, protrusion of the tongue, and difficulty in swallowing with airway embarrassment. These incidents happen especially in the premolar and canine regions $[36,37]$. To prevent significant bleeding, the practitioner has to be able to identify the source of bleeding, which can be related to anatomical variants, medication or other diseases. The key factor to avoid bleeding is prevention facilitated by good preparation and analysis, radiographic and clinical, on a case-by-case basis [26, 38].

The present study provides indirect information on the possible patterns of the sublingual and submental arteries intramandibular distribution via LCs. One should notignore that the neurovascular content of such canals is individually variable, and a vascular content of the lingual canals does not mandatorily locate a certain artery. It should also be taken into account that the extramandibular anatomic variation related to the dominant arterial distribution in the floor of the mouth of the submental and sublingual arteries [39] increases the risk of life-threatening hemorrhaging of the floor of the mouth. The present study may suggest the importance of CBCT-based identification of LC topography, which could result in the increased success of oral implant osteointegration [39].

By 3D reconstructions of the mandibular body one could easily evaluate the intramandibular canals for their position, 
number and anastomosing pattern. This study revealed the symmetrical bilateral aspect of the LLCs placed below the second premolar.

\section{References}

1.HIRSCHFELD I, J Am Dent Assoc, 14, nr. 4, 1927, p. 617-31

2.ENNIS LM, Int J Ortho Oral Surg, 23, nr. 2, 1937, p. 173-93

3.VON ARX T, LOZANOFF S, Clinical Oral Anatomy: A Comprehensive Review for Dental Practitioners and Researchers, Springer, 2016, p. 4.ROSANO G, TASCHIERI S, GAUDY JF, TESTORI T, DEL FABBRO M, Clin Oral Implants Res, 20, nr. 8, 2009, p. 791-5

5.TEPPER G, HOFSCHNEIDER UB, GAHLEITNER A, ULM C, Int J Oral Maxillofac Implants, 16, nr. 1, 2001, p.

6.NAITOH M, NAKAHARA K, SUENAGA Y, GOTOH K, KONDO S, ARIJIE, Oral Surg Oral Med Oral Pathol Oral Radiol Endod, 109, nr. 1, 2010, p. e25-31

7.BABIUC I, IOANA T, MIHAELA P, Rom J Morphol Embryol, 52, nr. 3, 2011, p. 827-9

8.SHEIKHI M, MOSAVAT F, AHMADI A, Dent Res J , 9, nr. Suppl 1, 2012, p. S45

9.CHOI D-Y, WOO Y-J, WON S-Y, KIM D-H, KIM H-J, HU K-S, J Craniofac Surg, 24, nr. 4, 2013, p. 1403-7

10.LIANG $X$, JACOBS R, LAMBRICHTS I, VANDEWALLE G, Clin Anat, 20, nr. 3, 2007, p. 246-51

11.VON ARXT, MATTER D, BUSER D, BORNSTEIN MM, J Oral Maxillofac Surg, 69, nr. 11, 2011, p. 2777-85

12.AOUN G, NASSEH I, SOKHN S, RIFAI M, J ournal of clinical imaging science, 7, nr. 2017, p. 16

13.TAGAYA A, MATSUDA Y, NAKAI IMA K, SEKI K, OKANO T, Clin Oral Implants Res, 20, nr. 4, 2009, p. 351-5

14.MCDONNELL D, NOURI MR, TODD M, J Anat, 184, nr. Pt 2, 1994, p. 363

15.SUTTON R, Aust Dent J, 19, nr. 3, 1974, p. 167-73

16.MADEIRA MC, PERCINOTO C, DAS GRACAS MSM, Oral Surg Oral Med Oral Pathol, 46, nr. 5, 1978, p. 608-14

17.LIANG $X$, JACOBS R, LAMBRICHTS I, VANDEWALLE G, VAN OOSTVELDT D, SCHEPERSE, et al., Dento maxillo facial radiology, 34, nr. 6, 2005, p. 362-8

18.PREDOIU M, RUSU MC, CHIRITA AL, Morphologie : bulletin de I'Association des anatomistes, nr. 2019, p.
19.RUSU MC, CIULUVICA RC, VRAPCIU AD, CHIRITA AL, PREDOIU M, MARU N, Folia Morphol (Warsz), nr. 2019, p.

20.CRAIU C, RUSU MC, HOSTIUC S, SANDULESCU M, DERJ AC-ARAMA Al, Anat Sci Int, 92, nr. 1, 2017, p. 98-106

21.RUSU MC, MARU N, RADOI PM, DINCA D, Surg Radiol Anat, 41, nr. 2, 2019, p. 231-4

22.RUSU MC, SAVA CJ, ILIE AC, SANDULESCU M, DINCA D, Ear Nose Throat J, nr. 2019, p.

23.SAVA CJ, RUSU MC, SANDULESCU M, DINCA D, Surg Radiol Anat, 40, nr. 7, 2018, p. 847-53

24.RUSU MC, MARU N, SAVA CJ, SANDULESCU M, DINCA D, Morphologie : bulletin de l'Association des anatomistes, 103, nr. 341, 2019, p. 54-9 25.RUSU MC, SANDULESCU M, SAVA CJ, DINCA D, Folia Morphol (Warsz), 78, nr. 1, 2019, p. 199-203

26.RUSU MC, SANDULESCU M, BICHIR C, MUNTIANU LAS, Ann Anat, 214, nr. 2017, p. 75-9

27.RUSU MC, DIDILESCU AC, JIANU AM, PADURARU D, Surg Radiol Anat, 35, nr. 2, 2013, p. 143-59

28.KATAKAMI K, MISHIMA A, KURIBAYASHI A, SHIMODA S, HAMADA Y, KOBAYASHI K, Clin Oral Implants Res, 20, nr. 4, 2009, p. 386-90

29.KILIC E, DOGANAY S, ULU M, ÇELEBI N, YIKILMAZ A, ALKAN A, Clin Oral Implants Res, 25, nr. 2, 2014, p. e90-e3

30.SEKERCI AE, SISMAN Y, PAYVEREN MA, Surgical and Radiologic Anatomy, 36, nr. 9, 2014, p. 857-64

31.SCARAVILLI MS, MARINIELLO M, SAMMARTINO G, EurJ Radiol, 76, nr. 2, 2010, p. 173-6

32.KATAKAMI K, MISHIMA A, KURIBAYASHI A, SHIMODA S, HAMADA Y, KOBAYASHI K, Clin Oral Implants Res, 20, nr. 4, 2009, p. 386-90

33.CARTER R, KEEN E, J Anat, 108, nr. Pt 3, 1971, p. 433

34.SHILLER WR, WISWELL OB, Anat Rec, 119, nr. 3, 1954, p. 387-90 35.SHIRAI M, Yokohama medical bulletin, 11, nr. 1960, p. 541-9

36.KALPIDIS CD, KONSTANTINIDIS AB, Implant Dent, 14, nr. 2, 2005, p. 117-24

37.SAINO M, AKASAKA M, NAKAJIMA M, KAYAMA T, KONDOH R, NAGAHATA M, et al., No shinkei geka Neurological surgery, 25, nr. 9, 1997, p. 835-9

38.QUIRYNEN M, MRAIWA N, VAN STEENBERGHE D, JACOBS R, Clin Oral Implants Res, 14, nr. 3, 2003, p. 280-5

39.KATSUMI Y, TANAKA R, HAYASHI T, KOGAT, TAKAGI R, OHSHIMA H, Clin Oral Implants Res, 24, nr. 4, 2013, p. 434-40

Manuscript received: 27.06 .2018 